\title{
O DESIGN ENQUANTO LINGUAGEM: possíveis desdobramentos estéticos
}

Design as a language: possible aesthetics developments

\author{
Martina Viegas ${ }^{1}$ \\ Universidade Feevale \\ martina.viegas@gmail.com \\ Lurdi Blauth $^{2}$ \\ Universidade Feevale \\ lurdib@feevale.br
}

\begin{abstract}
Resumo: O presente estudo discorre sobre conceitos de estética e de estetização do design enquanto linguagem visual na contemporaneidade. Através da arte propiciam-se desdobramentos estéticos capazes de configurar uma linguagem visual que legitima o design dentro do contexto de construção de sentidos no que tange o consumo enquanto manifestação cultural e social inserida no cenário hiperestético proposto por Wolfgang Welsh, analisado através da obra de arte de Beto Schwafaty, Fundamentos da Substância do Design: metáforas culturais para projetar um novo futuro.
\end{abstract}

Palavras-chave: Estética, estetização, cultura, linguagem.

\begin{abstract}
The present study analyzes design aesthetics and aestheticization concepts as a visual language in present days. Through art, aesthetics developments are provided in order to create a visual language that legitimizes design in the context of sensory construction in regards to consumption as a cultural and social manifestation inserted into the hyper aesthetic scenario proposed by Wolfgang Welsh and analyzed through the artwork of Beto Schwafaty (Foundation of Design Substance: cultural metaphors to projecting a new future).
\end{abstract}

Keywords: Aesthetics, aesthetization, culture, language.

\footnotetext{
${ }^{1}$ Mestranda em Processos e Manifestações Visuais, Universidade Feevale; Especialista em Design de Superfície; Graduada em Design, habilitação Design Gráfico, Universidade Feevale.

${ }^{2}$ Doutora em Artes Visuais, UFRGS; Artista visual, professora e pesquisadora; Lidera o projeto de pesquisa Imagem e Texto: inscrições e grafias em produções poéticas, Universidade Feevale. Orientadora deste projeto.
} 


\section{INTRODUÇÃO}

A arte propicia desdobramentos estéticos que auxiliam na configuração de uma linguagem visual da qual o design se apropria e alimenta, legitimando-se enquanto área do conhecimento a partir do momento em que articula a construção de novos sentidos em relação à sociedade material do consumo na contemporaneidade. Rafael Cardoso (2013) afirma que o design surgiu nos séculos XVIII e XIX com o propósito de organizar a produção industrial em série. Nesse período, o consumo de diversos bens já estava ao alcance da população, contudo, pensava-se que a produção em série, desenfreada, acarretaria perda de beleza e qualidade dos produtos. Gradativamente, ocorre a aproximação com profissionais provenientes de diferentes áreas criativas (como arquitetos e artistas, por exemplo), de governos e de instituições de ensino, de indústrias e de comerciantes, com o intuito de agregar também uma qualidade estética e visual nos produtos para estimular o consumo. $\mathrm{O}$ aspecto visual passou a indicar uma ascendente importância em detrimento da função do produto, embora fundamental, começam a ser vinculados com a criação de elementos formais de uma linguagem visual atraente, para proporcionar o sucesso de vendas.

Contudo, essa relação entre forma e função, enquanto fator central do pensamento criativo perdurou por bastante tempo, passando a ser contestado apenas após a segunda metade do século $X X$, sendo que no Brasil, tal pensamento permaneceu evidente até meados da década de 80. Em uma sociedade na qual os indivíduos mudam seus hábitos e preferências com o passar do tempo, é justo imaginar a construção cultural enquanto elemento igualmente mutante e, portanto, suscetível a uma série de reflexões que repercutem no design, na estética e no consumo e produção de novos produtos.

De fato, as sociedades complexas do contexto moderno-contemporâneo são caracterizadas por intensos processos de interação, nos quais a própria complexidade moderna associa-se ao mercado internacional através da globalização: o design e a arte tornam-se importantes condutores de troca cultural através da estética comercializada. Tal troca cultural pode ocorrer através da comunicação entre as massas, em viagens e encontros internacionais, relações sociais, econômicas e políticas (VELHO, 2013).

Perante este contexto marcado fortemente pelo consumo inserido em uma sociedade que apresenta as suas principais angústias decodificadas em produtos consumidos com pouca ou nenhuma reflexão, torna-se fundamental discutir e analisar os conceitos de estética dentro dos processos de estetização, buscando identificar quais são as marcas socioculturais capazes de apresentar o design enquanto linguagem, bem como repensar quais seriam os possíveis desdobramentos estéticos observados através da arte na contemporaneidade.

Para tanto, o estudo realiza pesquisa bibliográfica de conceitos e teorias acerca de estética e arte a partir de Wolfgang Welsh, amparados pelo conceito de identidade, cultura, mundialização e sociedade, de Stuart Hall. A pesquisa propõe enfatizar a contribuição do design enquanto manifestação cultural através do arcabouço teóricoconceitual de Deyan Sudjic e Patrícia Dalpra, apresentando o panorama da história do 
design e as perspectivas de criação perante o cenário hiperestético ${ }^{3}$ proposto por Welsh. Como desdobramento entre arte e design dentro do viés estético, analisa-se a obra de Beto Schwafaty, intitulada Fundamentos da Substância do Design: metáforas culturais para projetar um novo futuro, (2013).

\section{ESTÉTICA: CULTURA E SEUS PROCESSOS DE ESTETIZAÇÃO}

A construção cultural de uma sociedade faz-se, em primeiro lugar, a partir da construção biográfica de trajetória individual. Cada indivíduo, ao relacionar-se socialmente, acaba por trocar cultura com demais indivíduos inseridos em um mesmo contexto. Essa troca cultural pode, igualmente, ser verificada através da estética manifesta pela arte e pelo design através de produtos comercializados, constituídos por meio de processos de estetização. Tais processos de estetização são vivenciados individualmente e coletivamente, sendo que, conforme Velho (2013), o ser humano, enquanto ser individual moderno, nasce, cresce, desenvolve-se e vive inserido em uma determinada cultura e tradição experimentada em formato particular, assim como seus antepassados de todas as épocas e lugares do limitante espaço-tempo. Entretanto, o autor ressalta ainda, que esses indivíduos estão expostos, afetados e influenciados por sistemas de valores heterogêneos que possibilitam certa mobilidade material e simbólica, tratando-se de uma tendência geral que não deve ser compreendida por uma tendência generalista.

Nesse sentido, um dos indicativos dos processos de expansão da estetização pode ser verificado, por exemplo, em produtos extremamente semelhantes colocados à venda, dispostos um ao lado do outro, na mesma prateleira. Consumidores com maior ou menor poder aquisitivo obtêm estes produtos observando, muitas vezes, apenas a questão estética e visual e não a qualidade, a função ou mesmo a origem industrial do produto. Wolfgang Welsh (1995) oferece leituras interpretativas acerca da estética e dos processos de estetização que a vivenciados socialmente e experimentados na atualidade, trazendo exemplos que ilustram este contexto. $O$ autor relata, por exemplo, a questão das estações de trens alemãs que deixaram de se chamar estações ferroviárias, denominando-se de "emoções com conexões de trilhos" (erlebniswelt mit gleisanschluss) quando passaram a expor obras de arte.

Ao agregar novas funções aos serviços ou produtos já existentes, acredita-se na possibilidade de amplificação do campo de atuação do design enquanto linguagem, sendo que a estética adquire, então, fundamental importância. A criação de produtos com um design diferenciado, cada vez mais, desdobra-se para um formato estéticovisual que procura transcender aspectos apenas superficiais, estando atento para atingir com maior profundidade as relações com o comportamento humano. Desta forma, o design vale-se da estética enquanto veículo de propagação de seus conceitos visuais, buscando um caráter mais introspectivo, relacionando questões emocionais do consumidor. Welsh (1995) afirma que passamos diariamente do 'escritório das emoções' para o centro 'comercial de emoções', posto que a atualidade do consumo exija não apenas produtos esteticamente belos e funcionais, mas também produtos que ofereçam sensações e que oportunizem experiências.

\footnotetext{
${ }^{3}$ Welsh (1995) traz o conceito de cenário hiperestético para deflagrar a sociedade contemporânea como uma sociedade fortemente marcada pela cultura do materialismo, onde o visual e o estético tornaramse as principais diretrizes do comportamento e pensamento humanos em contexto social.
} 
Ao ter uma experiência estética, o indivíduo aciona aspectos intuitivos que estão relacionados com sua percepção diante de determinado produto. $O$ ato de "intuir" significa "registrar" o que se passa na consciência dos indivíduos que intuem todas as ações perceptivas que correspondem "ao ver, ao ouvir, ao tocar, ao cheirar, ao degustar" (GREENBERG, 2013, p. 63). Ou seja, o ato de intuir trata de uma ação individual, pois ninguém é capaz de intuir por outro alguém: a experiência, assim como a própria existência e o conhecimento são inconcebíveis sem a presença da intuição, do mesmo modo que a arte e a experiência estética. Greenberg (2013) reforça que, enquanto a intuição comum informa, instrui e oferece orientação, também aponta para novos caminhos: é a interpretação da intuição através da experiência estética que motivará o indivíduo a construir-se culturalmente diante da sociedade de consumo.

Arte, design e intuição, portanto, fundamentam-se enquanto essência do apuro estético que produz, além de apenas reproduzir. Greenberg (2013) estabelece que a partir do momento no qual a intuição individual deixa de apontar para algo novo, deixando de informar, ela transforma-se em uma intuição estética. Como tal, a intuição passa a ser usufruída - ou não, sustentada e direcionada apenas em nome de si e para si. A intuição estética que afirma que a cor do céu é azul deixa de informar como está o tempo e transforma o céu em objeto de análise apenas no que diz respeito a sua cor. A intuição comum é uma condição à estética, pois é preciso contar com os sentidos e estar atento para que se possa passar por qualquer experiência visual.

Nesse sentido, podemos indagar porque determinados indivíduos escolhem e adquirem, entre produtos extremamente parecidos, os mais acessíveis? Provavelmente, por reconhecer semelhanças com produtos de outras marcas mais conceituadas e, portanto, de custos e prestígio social mais elevados. Ao adquirir um produto financeiramente mais acessível, que se assemelha a um produto produzido por artistas ou designers de renome, o consumidor fortalece uma sociedade que adquire produtos sem analisar sua natureza, seus materiais e processos de produção, seu conforto - em tratando- se de roupas ou calçados, ou mesmo a sua qualidade e durabilidade. De um lado, isso significa que os indivíduos da sociedade atual procuram no imediatismo, o envolvimento aos apelos pragmáticos. Por exemplo, há uma avidez por novidades eletrônicas que propulsionam a programar (mesmo que indiretamente) a obsolescência pela qual os produtos comercializados são submetidos. De outro lado, também é preciso pensar que a simples situação de "recarregar as energias" em restaurantes elegantes e agradáveis, passa a alimentar não apenas o corpo, mas também, a alma: este exemplo citado por Welsh (1995) ilustra como a estética vem ramificando-se através dos processos de estetização vivenciados diariamente.

Diante da sociedade pós-moderna, imediatista e mecanizada, Jacques Rancière (2013) coloca que, de certa forma, a arte também se utiliza de meios mecanizados, referindo-se à introdução da fotografia e do cinema, para criar novas relações com o espectador. Essas novas técnicas de reprodução mecânica, propiciaram rupturas no campo da arte, principalmente no início de século $X X$, em relação ao sentido de representação, tempo e espaço que aproximam a arte da vida cotidiana. Nessa perspectiva, os meios de reprodução acompanham a velocidade provocada pela modernidade, sendo a fotografia e o cinema alguns dos propulsores da disseminação de uma nova visibilidade estética e perceptiva da realidade. 
Neste sentido, no entendimento de Jacques Rancière (2013), o regime estético das artes é o fim do sistema da representação, pois os processos de estetização não devem ser controlados pela hierarquia que define que o gênero tragédia é nobre, enquanto que o gênero comédia é popular, elevando ou baixando os temas artísticos. $\mathrm{O}$ ato de intuir e de sentir a arte e o design através da estética das obras e produtos é, acima de tudo, um ato individual. $O$ indivíduo passa por este processo de estetização de forma solitária, embora conviva em uma sociedade de consumo que permita e enfatize a sua aproximação e interação social através do ato de consumir.

No que tange a estética, a experiência alicerçada pela atenção e pela intuição oferecem ao ser humano a percepção de si perante o contexto no qual está inserido e relacionando-se socialmente e culturalmente. A construção cultural estética, por meio da intuição, tem seu início marcado pelo momento de observação de mundo e experimentação deste mundo perante o universo sensível (Greenberg, 2013).

\begin{abstract}
Mas eu iria ainda mais longe, com o apoio da experiência, e diria que as coisas que não são intuídas no modo primário, coisas que permanecem fora do alcance dessa forma de intuição, podem da mesma maneira ser intuídas esteticamente. Refiro-me a entidades como inferências, cadeias de raciocínios, conhecimento dedutivo. Contrariamente à intuição primária ou comum, a intuição estética não conhece limites. O que significa que qualquer coisa que entre no campo da atenção, pode ser intuída e vivenciada esteticamente. Por outras palavras, a intuição estética comanda o mundo como nada mais o faz - para a consciência humana (GREENBERG, 2013, p. 58).
\end{abstract}

Nesse sentido, torna-se fundamental diferenciar o que uma experiência estética é, do que esta experiência parece ser, pois a estética possui processos de estetização que podem e devem ser observados e estudados com cuidado.

Wolfgang Welsh (1995) apresenta duas versões de significação geral a respeito da estética e seus processos de estetização: 1) a confusão entre o ser e parecer; 2) a diferença entre hardware e software. Segundo o autor, o produto que antes era o "hardware", ou seja, o corpo essencial da questão, em termos mais técnicos, agora é simplesmente uma obra que ornamenta a emoção oferecida pelo objeto; a estética, ao contrário, que antes era o "software", espécie de complemento ao corpo físico formal do objeto, torna-se o principal. A estética se transformou em uma espécie de "valor monetário social", servindo como padrão de aceitação e fator definidor do consumo e apelo de mercado, sendo que, atualmente, o produto pode não ser um bom produto, mas precisa parecer um bom produto aos olhos de quem o adquire.

Quando se consegue ligar um produto a uma estética que interesse ao consumidor, o produto acaba vendendo-se quase que automaticamente, mesmo que não possua uma configuração técnica muito sofisticada: não é o produto que está sendo adquirido, pois o que está à venda é um estilo de vida estético associado a ele (Welsh, 1995) através de uma relação cultural e social obtida através da experiência sensível (Greenberg, 2013).

Ainda neste contexto de estetização, Welsh (1995) explica que este processo pode tratar-se de uma estetização superficial (tratando-se do embelezamento, animação ou das emoções em geral); de uma estetização radical (troca de posições entre hardware e software enquanto prioridade moderna do estético), ou de uma estetização (styling) dos sujeitos (rumo ao homo aestheticus), a qual transforma o 
indivíduo em um ser que considera a estética o princípio básico e fundamental de sua existência. Ao conceituar o indivíduo estético como homo aestheticus, o autor propõe o olhar subjetivo acerca da vida e realização pessoal dos indivíduos: o estético passou a predominar de tal forma, que o homo aestheticus tornou-se a figura em destaque. Esse "homem estético, é um ser sensível, hedonista", educado e de bom gosto.

Ao ressaltar o fascinante universo da realidade material que se deixa alterar em sua microestrutura através de intervenções inteligentes iniciadas e acompanhadas durante todo o processo de desenvolvimento pelo computador, Welsh (1995) diz que a realidade é algo moldável e leve, que mesmo submetida às durezas materiais mais extremas, é efeito de procedimentos amenos e estéticos. Assim, a realidade social está exposta a procedimentos de estetização radicais, tornando-se uma oferta modelável esteticamente da superfície até algo mais profundo de sua substância.

Em relação à questão dos "sujeitos autodeterminados e resistentes", (FOUCAULT, apud: WELSH, 1993), a estética da existência é mais contemplativa e dependente de fatores como tempo, processos de estetização e estilização. Hoje, os sujeitos estão bastante acomodados e conformados em relação à estetização, algo que Welsh conceitua como "os novos zumbis". Para que o indivíduo não se torne um "zumbi" que apenas consome por consumir, esse indivíduo precisa possuir uma identidade forte e sólida, estando apto a interagir em uma sociedade sensível para experimentar a estética que o cerca sem perder sua essência.

Por outro lado, Stuart Hall (2001) aprofunda seus estudos acerca de questões que norteiam a identidade cultural na atualidade, analisando se de fato existe uma 'crise de identidade', e, se esta existe em que consiste e quais as implicações de sua existência. $\mathrm{O}$ autor procura estabelecer conexões entre os conceitos de identidade e os de sujeito, argumentando tais relações como pertinentes ao contexto de identidade cultural da qual participam, motivam e pertencem as culturas étnicas, raciais, linguísticas e religiosas, agindo de forma globalizada. Simpático à afirmação de que as identidades modernas estão sendo descentradas, deslocadas e fragmentadas, Hall possui uma visão bastante aberta às diferentes interpretações possíveis. Afirma que o assunto não apenas inquieta a comunidade científica, mas também à população em geral, visto que o próprio conceito de identidade é bastante abrangente, totalizador e complexo.

Complementando:

Para aqueles/as teóricos/as que acreditam que as identidades modernas estão entrando em colapso, o argumento se desenvolve da seguinte forma. Um tipo diferente de mudança estrutural está transformando as sociedades modernas no final do século XX. Isso está fragmentando as paisagens culturais de classe, gênero, sexualidade, etnia, raça e nacionalidade, que, no passado, nos tinham fornecido sólidas localizações como indivíduos sociais. Estas transformações estão, também, mudando nossas identidades pessoais, abalando a ideia que temos de nós próprios como sujeitos integrados (HALL, 2001, p.09).

O sentimento de 'perda de si' é chamado por Hall de deslocamento ou descentramento do sujeito. Desse modo, trata-se de um duplo descentramento, pois

\footnotetext{
${ }^{4}$ Um indivíduo hedonista é um indivíduo que prioriza o prazer e a supressão da dor como objetivo de vida, colocando as experiências acima de tudo.
} 
ao mesmo tempo em que o sujeito encontra-se fragmentado em relação a sua identidade individual, sente-se fragmentado, também, em relação a outros sujeitos "descentração dos sujeitos de seu lugar no mundo social e cultural", "descentração dos sujeitos de si mesmos". Para que o indivíduo possa estabelecer uma experiência estética através de sua intuição, entendemos que esse indivíduo precisa ser um sujeito capaz de construir-se e desconstruir-se perante suas observações quando focalizamos as indagações, também quando pensamos as possibilidades de criação e recriação estética em produtos resultantes do design.

Para compreender-se a estética enquanto processo em gradual e progressiva construção, é preciso analisar e contextualizar o momento social e cultural vivenciado. A cultura estética nasce dos movimentos sociais e comportamentais regidos pela ação frenética do tempo frente à globalização e compartilhamento de informações, cada vez mais intenso. Dentro desse cenário, conforme Welsh (1995) o ser humano localizase enquanto indivíduo capaz de atuar nesses processos de construção da cultura estética. Entretanto, para que esta interferência ocorra de forma a agregar positivamente ao processo de estetização, não basta apenas coexistir nesse cenário, mas observar e agir no que tange ao seu local natural e seu posicionamento em relação à globalização e trânsito de informações compartilhadas.

Ortiz (1996), ao trazer o conceito de sujeito enquanto cidadão do mundo, faz alusão aos cidadãos mundiais que, mesmo quando não deslocados espacialmente, estabelecem uma ponte capaz de conectá-los ao mundo cotidiano. Esta reflexão sobre a amplitude da globalização sugere, à primeira vista, que ela se afaste das particularidades, pois trata-se do conceito de mundo enquanto fator abrangente que abraça as especificidades pertencentes à totalidade. No entanto, esse indivíduo precisa valer-se da constante atualização em termos de informação para permanecer conectado ao mundo que o cerca, estabelecendo relações capazes de auxiliar na construção da cultura e de sua própria identidade.

Diante desses fatores, o método da observação aproxima o ser humano do que ele deseja compreender, trazendo às empresas que comercializam as marcas de sucesso, traços evidentes da manifestação da globalização (Lipovetski, 2013) por não apenas invadirem as casas dos consumidores, mas também libertar ou aprisionar as identidades individuais facetadas culturalmente na pós-modernidade (Hall, 2001).

A relação indivíduo versus mundo modifica hábitos, comportamentos e valores (Ortiz, 1996), sendo que o sentimento de pertencimento - a um determinado local, a uma etnia, a uma filosofia de vida, a uma cultura, acaba por ganhar novos e mais abrangentes significados, vivenciados também através da arte e do design. Entretanto, pertencer a um determinado local não significa desconhecer os demais ou não importar-se com os demais locais: pelo contrário, o sujeito passível de transformações estéticas é o sujeito capaz de locomover seu pensamento às experiências que the agreguem maior conhecimento acerca de si e do seu objeto de observação e estudo.

Ortiz (1996, p. 09), ao falar sobre a relação de pertencimento, acrescenta:

Neste sentido, não falo como brasileiro, ou latino-americano, embora saiba que no fundo é impossível, e indesejável, liberar-me totalmente desta condição. Mas como todo "cidadão mundial". Alguém que, situando-se num determinado lugar do planeta, resolveu enxergá-lo de todos os pontos [...] Não quero com isso desvalorizar uma visão territorializada. [...] a reflexão deve alçar voo, desprendendo o pensamento do peso de nossa herança intelectual. Talvez desta 
forma possamos compreender a problemática nacional com outros olhos.

Assim, diante de uma visão mais ampliada de mundo, embora não possamos deixar de pensar sobre as influências e heranças culturais e sociais, no entendimento de Welsh (1995), a estetização não deve ser nem aceita, nem rejeitada em âmbito total, posto que ambas as situações, se adotadas sem critérios, seriam inverdades práticas. Para o autor (1995) é inegável perceber que os processos de estetização são abrangentes e irrefutáveis, ressaltando que devido ao fato de não poder-se negar os processos de estetização, faz-se fundamental não esquecer que tais processos devam ser analisados e questionados. Argumenta, ainda, que se a sociedade for capaz de olhar para as implicações sociais que a cultura estética oferece, será possível sensibilizar a sociedade para as diferenças e consequente construção de uma cultura estética sadia capaz de atualizar o estético sem invalidar os questionamentos necessários para essa construção.

De forma complementar, Greenberg (2013) afirma que se qualquer objeto pode ser intuído através da estética, então qualquer objeto pode ser vivido e intuído artisticamente, sendo que a arte não pode ser separada da experiência estética em geral. A arte submetida ao teste da experiência não dependente do saber fazer, mas da ação de distanciamento que a observação artística precisa possuir para que mantenha um posicionamento estético abrangente e sem preconceitos.

Desse modo, assim como Welsh (1995) afirma que a tríade formada pela justificação (a nível de princípios e processos de estetização); a crítica (específica aos determinados processos de estetização) e o desenvolvimento (em relação às chances de sensibilização da estetização) podem auxiliar no processo de construção de sentenças justas dentro da estética, tais afirmações reforçam que o design e a arte são manifestações culturais de tais processos.

\section{O DESIGN ENQUANTO LINGUAGEM VISUAL - BETO SCHWAFATY E SUA OBRA FUNDAMENTOS DA SUBSTÂNCIA DO DESIGN: METÁFORAS CULTURAIS PARA PROJETAR UM NOVO FUTURO}

Vivemos em um momento de extrema obsolescência programada, na qual os produtos são projetados e concebidos levando-se em conta a projeção limitada de sua vida útil. O homo aestheticus, por exemplo, sabe que o modelo de telefone celular que possui funciona perfeitamente, contudo, troca esse aparelho por uma versão nova, mais atraente visualmente e com mais funções interativas. Ou seja, os produtos continuam funcionando, mas são trocados por modelos novos, frutos do processo de estetização. Estas são algumas das questões cada vez mais abordadas pelo design que busca desenvolver uma linguagem com apelo estético, no intuito de configurar um atrativo de vendas.

Percebemos que no momento atual, as antigas definições destinadas ao design, em relação às habilidades que comportavam o bom desempenho das funções de um produto, estão sendo marginalizadas e descartadas, salientando-se a sua natureza efêmera, a quantidade e o tempo de existência no mercado. Os produtos e os objetos estão aliados a determinadas qualidades estéticas que precisam estar em conformidade com as tendências comportamentais, culturais e sociais atuais. 
Para Deyan Sudjic (2008, p.21):

Muitas categorias de produtos foram não só transformadas e sim completamente eliminadas. Vivemos um período que, como as extinções dos grandes dinossauros, exterminou os bichos que rondavam a paisagem da primeira era industrial. E no rastro das extinções o processo evolutivo se acelerou tão violentamente que fugiu ao controle. Aqueles objetos industriais que sobreviveram têm um ciclo de vida medido em meses, não mais em décadas. Cada nova geração é surpreendida tão depressa que nunca dá tempo de desenvolver uma relação entre dono e objeto.

Diante de um mundo globalizado, cujas mudanças estão cada vez mais aceleradas, entendemos que é fundamental repensar sobre como essas trocas constantes influenciam, ou mesmo, o que tudo isso provoca na percepção do ser humano atual. E, dentro dessas mudanças e influências globalizadas, qual seria a participação do design hoje? Se tudo é descartado tão rapidamente, como o design, pode evocar uma identidade estética com uma visualidade que reflita sobre aspectos culturais de forma mais original? Ao ser articulado como linguagem visual, o design encontra-se contextualizado na discussão polarizada entre estilo e substância - pois ambos são característicos ao produto enquanto objeto de análise estética.

Dessa forma, Deyan Sudjic (2008) traz que, em muitos casos, é a superfície aparente e suas nuances que permitem a interpretação acerca da significação de um objeto. Dentro desse contexto, o autor reforça o conceito de designer narrador, destacando que o design é uma linguagem que deve ser emitida de modo fluido e eficaz, evitando ruídos e confusões ao consumidor que a adquire de forma implícita no ato da compra de um produto. O consumidor adquire um produto, mas compra, também, uma história narrada por este produto.

A partir dessas abordagens, percebemos a importância de refletir, nesse estudo, sobre o papel do design enquanto linguagem visual e estética na concepção de produtos, sobretudo em relação ao processo de retomada estratégica que valide a identidade do design no combate as réplicas demasiadamente inspiradas em produtos europeus e americanos. Estando o sujeito em meio a estas indagações, todas as relações por ele estabelecidas em meio cultural e social ficam abaladas. Por isso, torna-se fundamental o reforço da identidade do design, pois conforme Auroux (2009, p. 08), "cada um de nós encontra-se imerso na linguagem como em seu lugar natural, ali onde dominamos nossa presença no mundo e nossa humanidade". O design, ao narrar uma história, comunica através de sua própria linguagem - a estética.

Ao analisar-se o design enquanto possível desdobramento estético proveniente da arte, citamos a obra de Beto Schwafaty intitulada Fundamentos da substância do design: metáforas culturais para projetar um novo futuro (2013). Essa instalação foi exposta durante a 9a Bienal do Mercosul (2013), em Porto Alegre, Rio Grande do Sul (Figura 1). A estrutura em madeira, metal e vidro desenvolvida por Schwafaty (2013) resultou da pesquisa que o artista realizou junto aos arquivos e antigos espaços da empresa italiana Olivetti. Cabe mencionar que a empresa Olivetti despontou, em 1950, como um dos maiores ícones da indústria italiana, fabricando computadores, calculadoras e máquinas de escrever. De acordo com Schwafaty, a Olivetti decidiu estruturar uma série de projetos com a missão de projetar para uma sociedade democrática, um futuro progressista, levando em consideração a questão econômica, cultural e social. 
Através de iniciativas interdisciplinares, a Olivetti contou com sociólogos, designers, artistas, psicólogos e arquitetos para a elaboração destes projetos radicais e progressistas. De acordo com as informações colocadas junto com a obra, Schwafaty, o esforço da Olivetti era "coletivo no sentido de propor novas dinâmicas tanto para o mundo do trabalho, quanto para a sociedade que ascendia à luz dos novos paradigmas: a velha dicotomia homem versus máquina deveria ser superada por meio da conciliação entre a humanidade e as novas tecnologias. Forjada pela fusão da produção artística e industrial, eles seriam responsáveis pela emergência de um ambiente onde a informação daria a tônica ao surgimento de uma cultura imaterial". A figura 1 mostra a instalação de Schawafaty e destaca alguns dos elementos presentes na obra.

Figura 1 - Obra de Beto Schwafaty

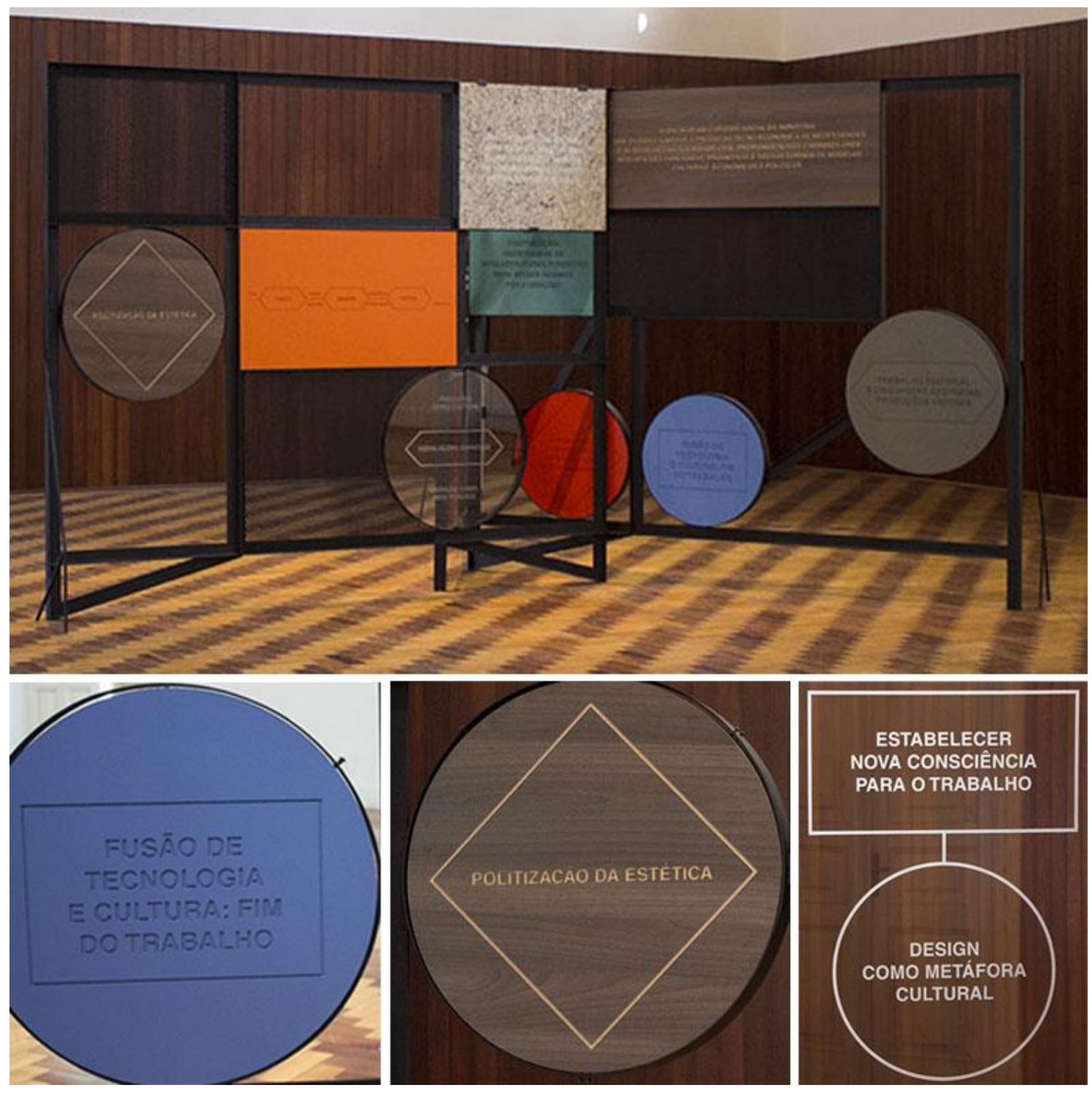

Fonte - Beto Schwafaty (2013), montagem realizada pela autora 
Nessa obra, o artista reinterpreta displays, objetos, arquitetura e propaganda que, "constituem não apenas peças de design ou comunicação, mas "vestígios arqueológicos" do inovador programa da Olivetti". A obra possui conceitos que resumem o espírito da empresa e ilustram o design enquanto linguagem visual dentro do estudo da estética. Dentre os conceitos trazidos por esta obra, destacam-se: fusão de tecnologia e cultura enquanto fim do trabalho; as produções híbridas (compreendidas como interdisciplinares, pelo artista) enquanto resultantes do trabalho imaterial e linguagens abstratas; o imaginário industrial enquanto imaginário de máquinas que produzem máquinas; o estabelecimento de uma nova consciência para o trabalho, encarando o design enquanto metáfora cultural, dentre outros conceitos que aparecem escritos em superfícies de vidro, granito, metal e madeira.

Podemos observar, nessa instalação artística de Schwafaty (2013), a proposição de reflexões presentes na atualidade, além do ponto de vista que a empresa Olivetti já manifestava e de sua preocupação na década de 50, apresentando e introduzindo o design enquanto fluxo resultante da ação plural e interdisciplinar oriunda de um pensamento estético aliado com a transformação cultural e social.

Ao mesmo tempo, Patrícia Dalpra (2009) apresenta um cenário no qual as novas tecnologias estão inseridas e são agentes contribuintes de reforço às possibilidades cognitivas e criativas. Dalpra relaciona tais possibilidades com o compartilhamento de projetos que viabilizam a possibilidade de conceber "um novo mundo" de modo original e inovador: o Design Thinking - o pensar design - e o consumo autoral podem e devem ser propiciados pelas ideias dos designers e gestores criativos.

\footnotetext{
As relações entre consumo e identidade no mundo contemporâneo, considerando que o estudo da relação entre uma determinada cultura local e o sistema de consumo que experimenta pode ser crucial para o conhecimento do modo de vida daquela cultura, suas práticas, seu imaginário, suas diferenças e singularidades diante de um quadro de informações, sensibilidades e ideologias globais (DALPRA, 2009, p. 12).
}

Tratando-se da identidade brasileira, Dalpra (2009, p.12) complementa que "cultura e consumo remetem à articulação entre identidade local e espírito do tempo presente, abrindo espaço para uma legião de ideias, teorias e pesquisas. [...] a cultura é o centro da reflexão antropológica, a identidade brasileira é o debate permanente sobre nossa especificidade e o consumo é o fenômeno capaz de nomear o mundo no qual vivemos".

Podemos apreender, então, que o consumo é outro desdobramento do processo de estetização pós-moderno, sendo que Rafael Cardoso (2013) afirma ser preciso contextualizar o design enquanto linguagem, a fim de encaminhar o pensamento do consumidor para a aquisição consciente de produtos projetados com apuro estético. Sendo a estética imaterial enquanto conceito, manifesta de forma material nos produtos comercializados, Cardoso (2013) lembra que é importante pensar sobre a agilidade com que o imaterial é capturado e traduzido em material, pois caso contrário, o design torna-se mecanismo supérfluo de fabricação. $O$ autor (2013) afirma, ainda, que o grande desafio do designer é o de ajustar pontos comuns entre situações desconexas, chamando a esta relação como o "ato de projetar interfaces": interfaces que possuem apelo estético e que representam o design 
enquanto linguagem visual capaz de projetar um mundo sensível, conforme ilustrado pela obra de Schwafaty (2013).

\section{BREVES CONSIDERAÇÕES FINAIS}

Esta pesquisa ainda encontra-se em andamento, pois é parte do estudo que vem sendo desenvolvido pela autora. Entretanto, é possível destacar algumas breves considerações finais.

As relações dos indivíduos - consigo e entre si - estão também determinadas pelos processos estéticos. Estas relações são fundamentais no processo de estetização social vivenciada nas sociedades pós-modernas. Tratando-se de um processo abrangente, tais relações configuram exemplos do quanto a estética é importante, considerando-se pequenos e grandes exemplos diários. Ao cortarmos nosso cabelo, desejamos um corte semelhante ao da atriz da novela; ao comprarmos um calçado novo, buscamos a opção mais semelhante ao modelo desfilado e destacado pela mídia; ao sairmos para almoçar, optamos pelo restaurante que recebeu o cantor de sucesso do momento: estes e tantos outros exemplos tornam-se importantes para a compreensão de que se a estética em sua totalidade é importante a este nível, o design pode ser considerado uma linguagem, pois contribui, desta forma, para a cadeia de propagação dos processos de estetização cultural submetidos à sociedade contemporânea.

Este assunto possui peso e significado suficiente para questionar, exigir e legitimar uma área de pesquisas que além de ocupar seu devido lugar no centro de preocupações das ciências sociais, seja capaz de propiciar a retomada do pensamento estratégico que identifique e reconheça a potencialidade criativa do profissional que compreende a sua sociedade e que projeta produtos que possuem a essência estética dotada de significado que transcende a aparência.

Obviamente, este ato de projetar é bem maior do que parece, pois exige do designer um envolvimento mais abrangente do que apenas o relacionado ao seu trabalho em frente ao computador. O designer contemporâneo precisa ter um trabalho que sirva de fio condutor que perpassa pelas diferentes áreas do conhecimento de forma plural e interdisciplinar, valendo-se dos conceitos pertinentes a cada área do conhecimento e fazendo, destes, pontos culminantes para a sua compreensão de mundo. A obra de Beto Schwafaty representa, desta forma, o exemplo das possibilidades desencadeadas entre arte e design enquanto linguagem visual e a fundamentação no estudo da estética, desdobrando-se enquanto universo sensível capaz de ser partilhado enquanto experiência individual e coletiva frente aos processos de estetização vivenciados atualmente.

\section{REFERÊNCIAS}

Associação Brasileira de Normas Técnicas. NBR 6021: Apresentação de periódicos. Rio de Janeiro, 1994.

AUROUX, Sylvain. Filosofia da Linguagem. São Paulo: Editora Parábola, 2009.

CARDOSO, Rafael. Design para um mundo complexo. São Paulo: Cosacnaify, 2013. 
DALPRA, Patrícia. DNA Brasil - Tendências e conceitos para as cinco regiões brasileiras. São Paulo: Editora Estação das Letras e Cores, 2009.

GREENBERG, Clement. Estética Doméstica: observações sobre a arte e o gosto. São Paulo: Cosacnaify, 2013.

GREENBERG, Clement. Arte e Cultura: ensaios críticos. São Paulo: Cosacnaify, 2013.

HALL, Stuart. A Identidade Cultural na Pós-Modernidade. 6ạ Edição. Rio de Janeiro: DP\&A editora, 2001.

LIPOVETSKY, Gilles. O império do efêmero: A moda e seu destino nas sociedades modernas. 3a reimpressão. São Paulo: Companhia de Bolso, 2013.

ORTIZ, Renato. Mundialização e cultura. 2ạ. ed. São Paulo: Braziliense, 1996.

RANCIÈRE, Jacques. A partilha do sensível: Estética e Política. São Paulo: Editora 34, 2012. Retirei a citação

SUDJIC, Deyan. A linguagem das coisas. Rio de janeiro: Intrínseca, 2010.

VELHO, Gilberto. Um antropólogo na cidade. Ensaios de antropologia urbana. Rio de Janeiro: Editora Zahar, 2013.

WELSH, Wolfgang. Estetização e estetização profunda ou: a respeito da atualidade do estético nos dias de hoje. Rio Grande do Sul (RS). UFRGS, 1995.

WELSH, Wolfgang. Undoing Aesthetics. Theory, Culture \& Society. Londres: Sage Publications, 1997.

SCWAFATY, Beto. Fundamentos da Substância do Design: metáforas culturais para projetar um novo futuro (Foundation of Design Substance: cultural metaphors to projecting a new future), 2013. Disponível na internet por http em: <http://www.shwafaty.org/>. Acesso em 15 fev. 2014. 